\title{
EFEKTIFITAS RANCANG BANGUN ALAT (BURNER) OLI BEKAS DALAM MENDUKUNG PROSES STERILISASI MEDIA JAMUR TIRAM (Pleurotus astreatus)
}

\author{
Disusun oleh : \\ Riza Trihaditia**) \\ Moch Lutvy Agustiawan*)
}

\begin{abstract}
Abstrak
Pasokan energi saat ini masih didominasi oleh sumber energi fosil yang tidak dapat diperbaharui yaitu minyak bumi, batubara, dan gas alam. Usahatani budidaya jamur tiram di Indonesia seringkali mengalami kerugian karena bahan bakar yang sering digunakan mengalami kenaikan harga yang tidak dapat diprediksi. Seperti yang kita ketahui bahwa sterilisasi jamur tiram menyita waktu yang cukup lama dan membutuhkan bahan bakar yang cukup banyak. Tujuan penelitian ini adalah untuk meningkatkan efektifitas proses sterilisasi media jamur tiram dengan menggunakan bahan bakar alternatif dari oli bekas untuk meningkatkan nilai ekonomis bagi usahatani jamur tiram. Penelitian ini bersifat eksperimental yang memanfaatkan oli bekas sebagai bahan bakar alternatif dan perangkaian menggunakan bahan yang terbuat dari besi yang dirancang seperti kompor. Pengujian alat ini dilakukan dengan menghitung waktu ignisi, pencapaian $100^{\circ} \mathrm{C}$, perbandingan jaring kawat pada kedua burner, efesiensi harga dan waktu pada kedua burner dan pengambilan data steril dan tidak steril pada baglog jamur. Hasil peneletian ini menujukan bahwa pada kedua burner, burner oli bekas dalam ignisi membutuhkan 5 menit, pencapaian syarat sterilisasi $100^{\circ} \mathrm{C}$ adalah 25 menit 05 detik dan waktu sterilisasi 4 jam 10 menit. Pada efesiensi harga dan waktu burner oli bekas mengeluarkan 6,5 liter dengan biaya 4.550 dari 700/liter dan baglog yang steril 10 dari pengujian 1 baglog yang tidak steril.
\end{abstract}

Kata kunci: Jamur Tiram, Burner, Oli bekas, sterilisasi.

\begin{abstract}
Energy supply is currently dominated by non-renewable fossil energy sources, namely oil, coal and natural gas. Oyster mushroom farming in Indonesia often experiences losses because the fuel often used experiences unpredictable price increases. As we know, oyster mushroom sterilization takes a long time and requires a lot of fuel. The purpose of this study was to improve the effectiveness of the oyster mushroom media sterilization process by using alternative fuels from used oil to increase the economic value of oyster mushroom farming. This research is an experiment that utilizes used oil as an alternative fuel and a series using materials made of iron designed like a stove. Testing of this tool is done by calculating ignition time, achieving $100^{\circ} \mathrm{C}$, comparison of wire mesh on both burners, price and time efficiency on both burners and sterile and non-sterile data collection on mushroom beams. The results of this study show that on both burners, the used oil burner in ignition takes 5
\end{abstract}


minutes, the attainment of $100^{\circ} \mathrm{C}$ sterilization requirements is 16 minutes 05 seconds and timer sterilization 4 hours 10 minutes. In the price and time efficiency of used oil burners remove 6.5 liters at a cost of 4,550 from 700 / liter and sterile oyster mushroom beams 10 from testing 1 unsterile beam.

Keywords: Oyster Mushroom, Burner, Used Oil, sterilization.

*) Alumni Fakultas Sains Terapan UNSUR

**) Dosen Fakultas Sains Terapan UNSUR 


\section{PENDAHULUAN}

Pasokan energi saat ini masih didominasi oleh sumber energi fosil yang tidak dapat diperbaharui yaitu minyak bumi, batubara, dan gas alam. Kenaikan harga minyak mentah dipasaran internasional berdasarkan data APBN (2019) mengasumsikan harga minyak mentah sebesar USD 48 per barel, sementara ini harga minyak dunia sudah naik hingga USD 70 per barel. Pemerintah berada dalam posisi yang dilematis kebijaksanaan untuk menaikkan harga penjualan BBM di dalam negeri walaupun dapat mengurangi subsidi namun dampaknya akan dirasakan langsung oleh masyarakat maupun industri kecil yang sangat besar ketergantungannya di bidang transportasi dan energi. Sementara itu dengan tidak menaikkan harga BBM, dengan harga minyak dunia yang tinggi, subsidi yang diberikan Pemerintah akan membesar sehingga mengurangi kemampuan untuk membiayai pembangunan di sektor lain (Haryanto, 2014 dalam Afrian, 2017).

Hal ini secara jelas membuktikan bahwa Indonesia sudah merupakan net oil importer country dimana walaupun merupakan negara pengekspor minyak namun kebutuhan BBM di Indonesia sudah sedemikian tinggi sehingga perlu mengimpor minyak dalam jumlah besar. Sejak mencapai puncaknya pada tahun 1980-an, produksi minyak Indonesia yang pada waktu itu 1,6 juta barel/hari terus menurun hingga menjadi hanya 1,2 juta barel/hari. Sementara itu pertumbuhan konsumsi energy dalam negeri mencapai $10 \%$ per tahun (Indartono, 2005 dalam Raharjo 2009). Selama ini oli bekas baik yang berasal dari sepeda motor maupun mobil hanya menjadi limbah bagi lingkungan dan bahkan dapat mencemari perairan di sekitarnya.

Usahatani budidaya jamur tiram di Indonesia seringkali mengalami kerugian karena bahan bakar yang sering digunakan mengalami kenaikan harga yang tidak diprediksi. Perlu adanya perhatian dari pemerintah terhadap petani usaha jamur tiram. Jamur tiram adalah salah satu jamur yang sangat laku di pasaran saat ini sebagai salah satu bahan makanan. Namun jamur tersebut sangatlah sulit untuk ditemukan di alam saat ini dan kemunculannya juga hanya sedikit. Maka dari itu diperlukanlah suatu budidaya jamur tiram untuk memenuhi permintaan pasar dan tidak sedikit jamur yang berasal dari indonesia diimpor dari luar negeri. Selain sebagai bahan makanan produksi jamur tiram juga dapat menjadi sebuah usaha menjanjikan dan dapat mengurangi pengangguran yang ada saat ini karena pengangguran setiap tahun semakin meningkat.

Jamur tiram putih (Pleurotus ostreatus) merupakan salah satu jenis jamur kayu yang mempunyai prospek baik untuk dikembangkan sebagai diversifikasi bahan pangan serta kandungan gizinya setara dengan daging dan ikan. Jamur tiram putih dilihat dari segi bisnis menguntungkan karena harganya cukup tinggi, per kilogram bisa mencapai sepuluh ribu rupiah bahkan bisa lebih. Permintaan pasar lokal dan ekspor terbuka lebar, waktu panennya singkat sekitar 1-3 bulan, bahan baku mudah didapat, dan tidak membutuhkan lahan yang luas, oleh karena itu jenis jamur ini mulai banyak dibudidayakan (Agus, 2006 dalam Mufarrihah, 2009).

Jamur dapat diolah sebagai makanan diantaranya sup jamur, pepes jamur, salad, bahkan dapat diolah menjadi semacam crips, crispy, ataupun chip (Darnetty, 2006 dalam Mufarrihah, 2009).

Salah satu masalah dalam budidaya jamur tiram di Indonesia adalah media tanam (baglog) dalam proses sterilisasi hingga bahan bakar. Oleh karena itu harus ada bahan bakar alternatif untuk para usahatani jamur tiram. Bahan alternatifnya yaitu pemanfaatan oli bekas sebagai bahan bakar untuk proses 
sterilisasi. Untuk bahan bakar dalam proses sterilisasi ini belum pernah dilakukan sebelumnya. Maka dari itu perlu adanya penelitian tentang sterilisasi jamur tiram dengan berbahan bakar oli bekas untuk meningkatkan nilai ekonomis usahatani budidaya jamur.

\section{METODE PENELITIAN}

Penelitian ini dilaksanakan pada bulan Febuari 2019 sampai Maret 2019 dilaksanakan di dua tempat yakni perakitan burner di bengkel las rancaggong, Cianjur dan pengujian di Gubuk Jamur Royan Cianjur.

Alat yang digunakan pada penelitian ini yaitu jerigen 4 liter, selang, pipa stainless ukuran $1 / 2$ inch, pipa stainless ukuran 3 inch, pipa stainless ukuran 2 inch, blower dengan lubang 2 inch, seng plat, kran air, drum 20 liter, las karbit, thermometer suhu panas dan baut. Sedangkan bahan yang digunakan pada penelitian ini yaitu serbuk kayu, dedak halus, kapur, kantung plastik, karet gelang air dan oli bekas untuk bahan pembakaran sterilisasi.
Campuran bahan dimasukan ke dalam plastik transparan dengan ukuran $20 \times 35 \mathrm{~cm}$ dan tebal 0,5. Media harus dipadatkan agar terbentuk log yang baik. Media yang bagus adalah kepadatannya merata. Jangan lupa, ujung plastik bagian bawah ditusuk jari telunjuk supaya masak. Hal ini dilakukan agar bahan yang dimasukkan dan dipadatkan bisa duduk posisinya (tidak miring). Pengisian dilakukan tidak terlalu penuh, tapi disisakan $15 \mathrm{~cm}$ untuk pemberian bibit jamur tiram F2 dan memudahkan dalam mengikat baglog bisa dilihat digambar 3.1.

Percobaan ini menggunakan microsoft excel dengan analisis deskriptif data yang didapat kemudian disajikan dalam bentuk grafik dan tabel. Untuk kemudian dibandingkan, dibahas sehingga dapat ditarik kedalam kesimpulan.

\section{HASIL DAN PEMBAHASAN}

Pengujian ini adalah pengujian pertama burner ketika siap beroprasi dengan percobaan memasak air dengan kapasitas 5 liter dalam panci membutuhkan waktu berpa menit samapi titik didih bisa dilihat pada gambar 1 .

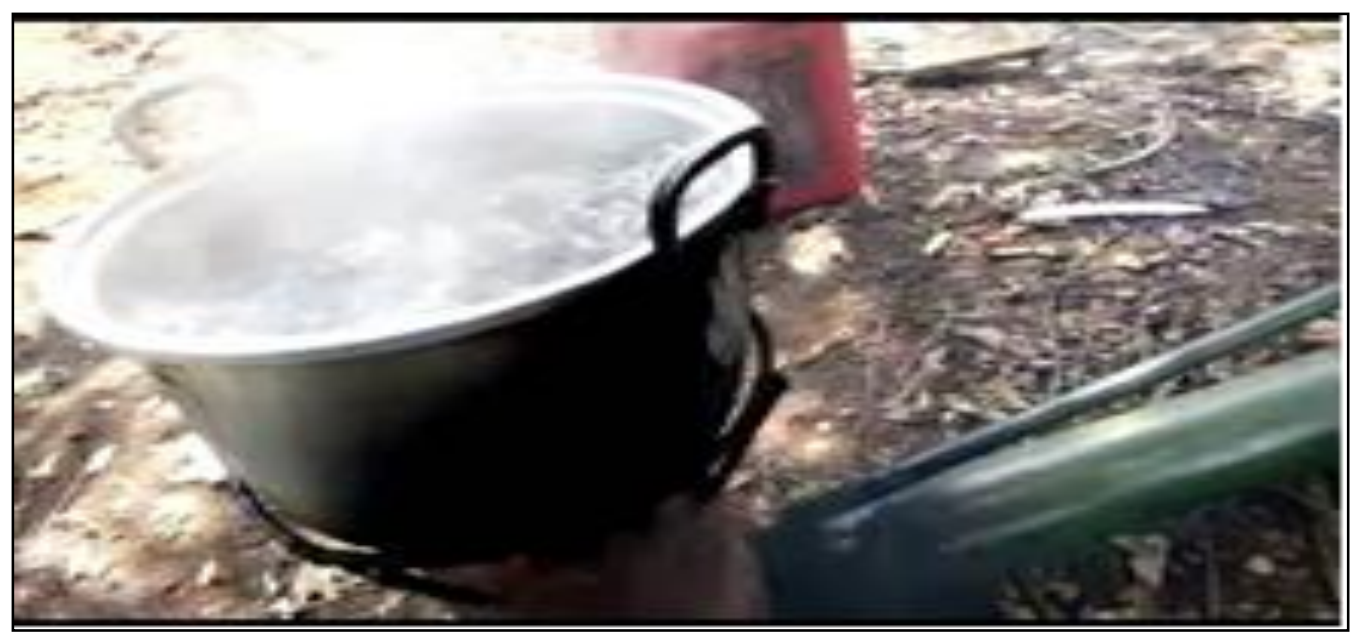

Gambar 1. (A) Memasak air berkapasitas 5 liter.

Percobaan ini dilakukan untuk mengetahui berapa detik dan menit burner oli bekas menyala dan kompor gas
LPG menyala dengan waktu yang bersamaan. Bisa di lihat pada tabel 1. 
Tabel 1. Hasil ignisi kedua burner.

\begin{tabular}{|c|c|c|}
\hline No & Ignisi ( Ignition) & Waktu (t) \\
\hline 1 & Burner Gas LPG & 1 detik \\
\hline 2 & Burner Oli Bekas & 5 menit \\
\hline
\end{tabular}

Hasil pada tabel 1. di atas menunjukan bahwa burner gas LPG lebih cepat dalam ignisi awalan pembakaran dengan membutuhkan waktu 1 detik sedangkan burner oli bekas membutuhkan waktu 5 menit untuk awalan pembakaran. Maka dari itu burner kompor gas lebih unggul dari pada burner oli bekas.

Burner gas LPG bersifat flammable karena flammable gas adalah gas yang mudah terbakar. Flammable gas bisa berupa compressed gas atau asap (vapor) dari hydrocarbon. Hydrocarbon adalah jenis bahan bakar yang mempunyai unsur Hydrogen dan Carbon $(\mathrm{C} \& \mathrm{H})$ seperti $\mathrm{CH} 4$

(Methane), C5H12 (Pentane). Sebagai contoh adalah LPG, mempunyai kandungan Propane (C3H6) dan Butane (C4H10), serta sejumlah kecil Etana (C2H6,) dan Pentane (C5H12). Flammable gas juga bisa terbentuk dari vapor dari zat yang bisa terbakar misal alkohol dan turunannya. Flammable gas bila bercampur dengan udara (oksigen) dan dengan komposisi yang tepat akan membentuk combustible atmosphere dan akan mudah terbakar (Dody Samudera, net all, 2018).

Oli bekas mengandung komponen logam berat. Polychlorinated Biphenyls (PCBs) Polycyclic Aromatic Hydrocarbons (PAHs) (susanto A, 2014). Minyak pelumas bekas juga mengandung beberapa logam berat seperti $\mathrm{Zn}, \mathrm{Al}, \mathrm{Ba}$, $\mathrm{Mg}, \mathrm{Mo}, \mathrm{K}, \mathrm{Ca}, \mathrm{Na}$ dan Pb. Bahan bakar yang digunakan dapat mengandung $\mathrm{Pb} 1$. Oli bekas juga bersifat flammable apabila tungku tersebut sudah panas pernyataan ini dalam jurnal (Akhyar, 2014). Pematik api menggunakan kayu bakar untuk memanaskan tungku karena burner oli bekas membutuhkan waktu untuk proses pembakaran.

Tabel 2. Hasil Pencapaian Kedua Burner dalam pencapaian $100^{\circ} \mathrm{C}$.

\begin{tabular}{|c|c|c|}
\hline No & Nama Burner & Waktu Pencapaian $100^{\circ} \mathrm{C}$ \\
\hline 1 & Oli bekas & 25 menit 05 detik \\
\hline 2 & Gas LPG & $1 \mathrm{Jam} 17$ menit \\
\hline
\end{tabular}

Berdasarkanhasil pengamatan table 2. menunjukan waktu yang dibutuhkan untuk mencapai $100^{\circ} \mathrm{C}$, burner oli bekas membutuhkan waktu 25 menit 05 detik dihitung dari ignisinya sedangkan burner gas LPG membutuhkan waktu 1 jam 17 menit 37 detik dihitung dari ignisinya.

Pada hasil di atas burner oli bekas unggul karena waktu yang diperlukan 25 menit, lebih cepat dari gas LPG dan burner oli bekas menggunakan tekanan angin dari blower menjadikan pembakaran menjadi optimal. Mengapa burner oli bekas menghasilkan suhu yang besar karena ruang pembakarannya tertutup menjadikan pembakaran berpusat tidak melebar.

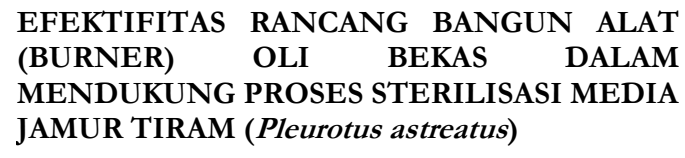

RIZA TRIHADITIA MOCH LUTVY AGUSTIAWAN 
Tabel 3. Hasil perbandingan menggunakan jaring kawat

\begin{tabular}{ccc}
\hline No. & \multicolumn{1}{c}{ Uraian Alat } & Waktu sterilisasi \\
\hline 1 & Burner tidak menggunakan jaring kawat & 3 jam 50 menit \\
2 & Burner menggunakan jaring kawat & 4 jam 10 menit \\
\hline
\end{tabular}

Hasil ditabel 3. menunjukan bahwa yang tidak menggunakan jaring kawat membutuhkan waktu 3 jam 50 menit saja dalam sterilisasi dan yang menggunakan jaring kawat membutuhkan 4 jam 10 menit.

Dalam proses pembakaran burner yang tidak menggunakan jaring

Tabel 4. Hasil efesiensi harga dan waktu sterilisasi.

\begin{tabular}{|c|c|c|c|c|}
\hline No. & Uraian alat & Waktu sterilisasi & $\begin{array}{l}\text { Bahan yang } \\
\text { dikeluarkan }\end{array}$ & Harga (Rp) \\
\hline 1 & Burner oli bekas & 3 jam 50 menit & 6 liter oli & 4.200.- \\
\hline 2 & $\begin{array}{l}\text { Burner oli bekas }+ \text { jaring } \\
\text { kawat }\end{array}$ & 4 jam 10 menit & 6,5 liter oli & 4.550.- \\
\hline 3 & Gas LPG & 5 jam 26 menit & $3 \mathrm{~kg}$ tabung & 25.000.- \\
\hline
\end{tabular}

Hasil pada tabel 4. menunjukan harga dan waktu sterilisasi yaitu burner oli bekas hanya menghabiskan 6 liter oli dalam sterilisasi selama 3 jam 50 menit, kemudian burner oli bekas menggunakan jaring kawat menghabiskan 6,5 liter dengan membutuhkan waktu 4 jam 10 menit dalam sterilisasi sedangkan burner gas LPG menghabiskan $3 \mathrm{~kg}$ tabung gas dengan waktu sterilisasi 5 jam 26 menit. kawat lebih unggul karena proses pembakaran tidak tertahan oleh jaring kawat. Tetapi apabila tidak menggunakan jaring kawat pembakaran dalam tungku akan menghasilkan asap yang cukup pekat dalam tungku.

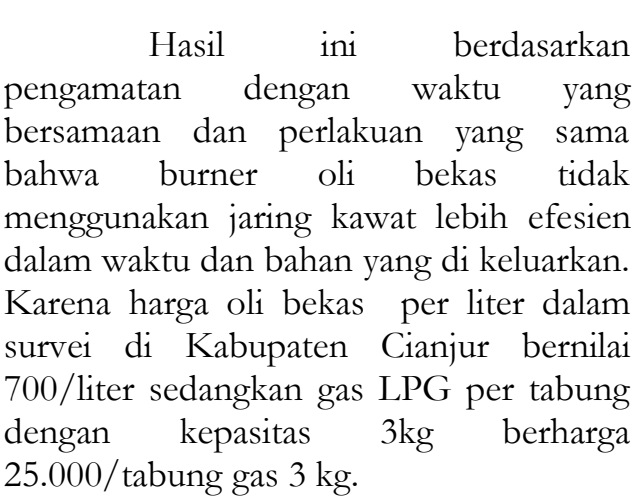


Tabel 5.Hasil baglog steril dan tidak steril.

\begin{tabular}{|c|c|c|c|c|}
\hline Uraian & Burrner & Jumlah Baglog & Steril & Tidak \\
\hline \multirow{20}{*}{$\begin{array}{l}\text { Bubuk Jamur } \\
\text { Kang Royan }\end{array}$} & \multirow{10}{*}{ Oli Bekas } & 1 & $\checkmark$ & \multirow{20}{*}{$\checkmark$} \\
\hline & & 2 & $\checkmark$ & \\
\hline & & 3 & $\checkmark$ & \\
\hline & & 4 & $\checkmark$ & \\
\hline & & 5 & $\checkmark$ & \\
\hline & & 6 & $\checkmark$ & \\
\hline & & 7 & $\checkmark$ & \\
\hline & & 8 & $\checkmark$ & \\
\hline & & 9 & & \\
\hline & & 10 & $\checkmark$ & \\
\hline & \multirow{10}{*}{ Gas LPG } & 1 & $\checkmark$ & \\
\hline & & 2 & $\checkmark$ & \\
\hline & & 3 & & \\
\hline & & 4 & $\checkmark$ & \\
\hline & & 5 & $\checkmark$ & \\
\hline & & 6 & $\checkmark$ & \\
\hline & & 7 & $\checkmark$ & \\
\hline & & 8 & $\checkmark$ & \\
\hline & & 9 & $\checkmark$ & \\
\hline & & 10 & $\checkmark$ & \\
\hline
\end{tabular}

Hasil pada tabel 5. menunjukan bahwa sterilisasi dengan dua alat yang berbeda memiliki hasil sama. Sterilisasi menggunakan burner oli bekas menghasilkan baglog yang steril berjumlah 9 baglog dan 1 baglog yang tidak steril dari 10 baglog dan gas LPG menghasilkan baglog yang steril berjumlah 9 baglog dan 1 baglog tidak steril dari 10 baglog. Untuk tingkat sterilisasi tidak ada perbedaan pada kedua burner tersebut karena kedua burner mencapai syarat sterilisasi dengan mencapai $100^{\circ} \mathrm{C}$.

\section{KESIMPULAN}

Dari penelitian yang dilakukan di usaha tani gubuk jamur kang royan dalam pembuatan burner oli bekas untuk sterilisasi jamur tiram dapat disimpulan yakni:

1. Burner oli bekas adalah kompor yang terbarukan untuk menjadikan kompor alternatif untuk meningkatkan nilai ekonomis usaha tani jamur tiram.

2. Tingkat efesiensi antara burner oli bekas dan burner gas LPG dalam penelitian ini adalah burner oli bekas.

3. Dalam ignisi burner gas burner oli bekas masih lambat karena oli bisa terbakar pada suhu tungku $\pm 200^{\circ} \mathrm{C}$.

4. Burner oli bekas sangat efesien dibandingkan burner gas LPG karena

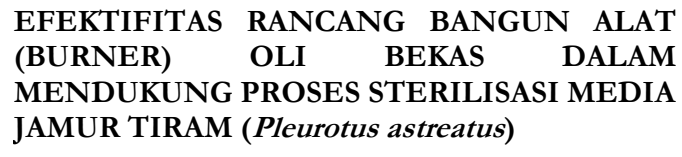

RIZA TRIHADITIA MOCH LUTVY AGUSTIAWAN 
waktu yang dihasilkan lebih cepat burner oli bekas dalam sterilisasi baglog jamur.

5. Burner tersebut menghasilkan waktu sterilisasi untuk mencapai $100^{\circ} \mathrm{C}$ hanya membutuhkan waktu 25 menit 05 Detik. dan untuk lamanya sterilisasi membutuhkan waktu 4 jam 10 menit dengan menghabiskan bahan 6,5 liter oli bekas. apabila dirupiahkan pada harga survei Kabupaten Cianjur 700/liter hanya mengeluarkan Rp 4.550.dibandingkan burner gas LPG yang membutuhkan waktu untuk mencapai $100^{\circ} \mathrm{C} 1$ jam 17 menit dan waktu sterilisasi 5 jam 26 menit dengan yang menghabiskan $3 \mathrm{~kg}$ tabung gas yang harganya Rp. 25.000.- / tabung 3kg.

6. Proses pembakaran burner oli bekas masih menggunakan bantuan kayu bakar untuk memanaskan tungku tersebut dan menggunakan bantuan alat yaitu jaring penghemat gas gunanya untuk menyaring asap supaya tidak menimbulkan asap yang pekat karena bisa mengganggu pada lingkungan.

\section{DAFTAR PUSTAKA}

Akhyar, 2014. Perancangan Dan Pembuatan Tungu Peleburan Logam Dengan Pemanfaatan Oli Bekas Sebagai Bahan Bakar. Jurnal. Fakultas Teknik. Universitas Syiah Kuala. Banda Aceh

Agus, GTK. 2002. Budidaya Jamur Konsumsi. Jakarta : Agro Media Pustaka.

Arif Susanto, 2014. Pengelolaan Limbah Minyak Pelumas Bengkel Kendaraan Bermotor Konsep Kesadaran Diri. Simposium Nasional. Pendidikan Teknik Otomotif. Universitas Muhhamadiyah Purworejo. ISSN 1412-9612

Chandra Afrian, 2017. Produksi Biogas Dari Campuran Kotoran Sapi
Dengan Rumput Gajah (Pennisetum Purpureum). Skripsi. Universitas Lampung. Bandar Lampung

Desna, 2010. Kajian Lamanya Proses Sterilisasi Media Jamur Tiram Putih terhadap Mutu Bibit Yang Dihasilkan. Skripsi. Fakultas Matematika Dan Ilmu Pengetahuan Alam. Institut Pertanian Bogor. Bogor

Dody Samudera, Ari Sugiharto, 2018. Sistem Peringatan dan Penanganan Kebocoran Gas Flammable dan Kebakaran Berbasis Internet Of Thing (IOT). Jurnal. Fakultas Teknologi Informasi dan Elektro. Universitas Teknologi Yogyakarta. VOL.01 NO.01 Maret

H. Parjimo, Drs. Agus Andoko. 2013. Budi Daya Jamur (Jamur Kuping, Jamur Tiram, Jamur Merang). Buku. Agromedia.

Isnaen wiardani, 2010. Budidaya Jamur Konsumsi. Dalam Menangguk Untung dari Budidaya Jamur Tiram dan Kuping. Buku. Lily Publisher.

Jahn Leonard Saragih, Welly Herumurti, 2013. Evaluasi Fungsi Insinerator dalam Memusnahkan Limbah B3 di Rumah Sakit TNI Dr.Ramelan Surabaya. Fakultas Teknik Sipil dan Perencanaan. Institut Teknologi Sepuluh Nopember. Surabaya. Vol. 2, No. 2,

Kementrian Keuangan Republik Indonesia. 2019. APBN 2019. https://www.kemenkeu.go.id/apb n2019.

Lailatul Mufarrihah, 2009. Pengaruh Penambahan Bekatul Dan Ampas Tahu Pada Media Terhadap Pertumbuhan Dan Produksi Jamur Tiram Putih (Pleorotus Ostreatus). Skripsi. Universitas Islam Negeri (Uin) Malang. hal: 1-2, 17-22.

R. D. Puspita (1), Desna (1), A.D. Husin (1), Irzaman (1), H.

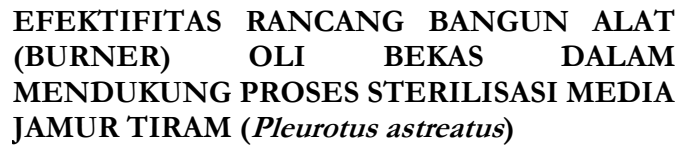


Darmasetiawan (1), Siswadi (2), 2010. Tungku Sekam Sebagai Bahan Bakar Alternatif Pada Sterilasasi Media Jamur Tiram. Institut Pertanian Bogor. Bogor. Vol 13. , No.2

Setyabudhi et al, 2017. Perancangan Sistem Kerja Kompor Ekonomis Dengan Bahan Bakar Oli Bekas. Program Studi Teknik Industri, Sekolah Tinggi Teknik Ibnu Sina. Batam.

Wahyu Purwo Raharjo, 2009. Pemanfaatan Oli Bekas Dengan Pencampuran Minyak Tanah Sebagai Bahan Bakar Pada Atomizing Burner. Jurnal. Universitas Sebelas Maret. Surakarta Vol. 10, No. 2, 2009: 156 - 168. 